\title{
Research Notes
}

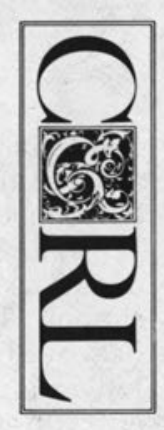

\section{An Investigation of Collection Support for Doctoral Research}

\section{Marion L. Buzzard and Doris E. New}

A major concern of bibliographers and other academic librarians involved in developing the collections of research libraries is, or should be, the amount and quality of support that is provided for the graduate programs of their institutions.

In carrying out their assignments, these librarians tend to rely chiefly on contact with the faculty for information. Since it is the faculty who shapes the curriculum for both undergraduate and graduate students and who also carries out most of the postdoctoral research, this seems a reasonable approach. It may, however, be less responsive to the needs of graduate research. Some doctoral research is related to the research interests of faculty advisers, but it would be unwise to assume the existence of such a connection without substantiation. And although there are faculty members who are conscientious in articulating the needs of their graduate students to librarians, as well as bibliographers who actively seek out these users, the latter are seldom identified as an essential contact point for selectors of library materials. It is possible, therefore, for a collection to support instructional and faculty research programs to a greater extent than the graduate programs that may strongly influence its scope and funding.
At the University of California, Irvine (UCI), collection development generally follows the traditional method of faculty contact to obtain most of the information used in making selection decisions. An additional source of information is provided through the use of interlibrary loan requests, which are forwarded to selectors after each transaction is completed. In order to evaluate the effectiveness of this approach, a study was devised to determine the actual level of support for doctoral research. A random sample of twelve dissertations completed at UCI in the humanities, sciences, and social sciences was selected for the study. The citations from these dissertations were divided into monographs and serials and were checked against the library's holdings. The results were expected to indicate where greater effort should be made to ascertain the needs of doctoral candidates at $\mathrm{UCI}$ and to support these needs with a reallocation of resources, if necessary.

\section{BACKGROUND}

Since the sixties, numerous attempts have been made to describe the relationship between the various types of academic programs and library resources in order to arrive at an understanding of what constitutes optimum or at least ade-

Marion L. Buzzard is head, Collection Development and Acquisitions, and Doris E. New is head, Serials Department, both at the University of California, Irvine. 
quate library support. ${ }^{1}$ Although these studies utilize both qualitative and quantitative methods of assessment, they have generally accepted the number of volumes owned as the most important indicator of support. This tendency was further codified by the development of the ClappJordan formula, which has had a lasting effect on standards for college and university libraries and the way in which research collections are funded. ${ }^{2}$

Like Clapp-Jordan, the revised standards for college libraries provided a formula for collection size that was weighted very heavily in favor of doctoral programs. ${ }^{3}$ Several years later the newly drafted standards for university libraries made a conscious attempt to deemphasize quantitative approaches but concluded that "nevertheless, quantitative measures are increasingly important in guiding the qualitative judgment that must ultimately be applied to university libraries and their collections. ${ }^{\prime 4}$

Whatever their faults, quantitative approaches have given libraries a convenient means of determining funding for their collections. As a case in point, since 1979 the University of California libraries have had their acquisitions funds allocated on the basis of a formula that bears more than a passing resemblance to its predecessors. ${ }^{5}$ Like them it awards volumes (which are then translated into dollars) largely according to the number and type of doctoral and graduate professional programs offered by each of the nine campuses. Because of the emphasis placed on these programs, it is highly desirable to be able to determine the support actually provided for doctoral research at UCI.

\section{RELATED RESEARCH}

Relatively few studies to date have focused on graduate students as a separate user group, and in almost all cases these have been limited to candidates for the master's degree and to a single discipline or field. A simple and fairly straightforward means of measuring the existing level of collection support for doctoral research is available by examining dissertations-the products of the research effort-to learn whether the references cited are held by the library. Citation analysis for this purpose, although recommended in library literature, has seldom been applied. A study by Popovich of thirty-one dissertations in the field of business/management had as a secondary aspect the determination of the extent to which the library owned the materials cited. However, less than half of the dissertations examined had been completed at that institution, thus precluding any direct correlation between the results obtained and the success of the collection in meeting the needs of its own doctoral students. $^{.}$

Citation analysis has long been used as a means of examining the characteristics of the literature cited by scientists and other scholars, and of singling out the most important journals in any particular field, usually the sciences. Peat proposes it as an acceptable technique for measuring research use of a research library, to complement circulation studies.' Other writers, such as Baughman and Voos, consider citation analysis a viable means, and perhaps the best objective approach, to collection evaluation. ${ }^{8}$

As with any quantitative measure, citation analysis must be applied with a recognition of its limitations; these have been well documented by Smith. ${ }^{9}$ The greatest weaknesses applicable to the study here described are (1) the assumption that all works cited were actually used by the researcher, and (2) the likelihood that there may have been a tendency to cite works that were accessible and to omit those that were not.

\section{HYPOTHESIS AND METHODOLOGY}

User studies published in the literature indicate that, on an average and regardless of size, libraries have acquired 90 percent of the materials requested by users. ${ }^{10}$ Without attempting to argue that this percentage constitutes either adequate or optimum support, we would nevertheless expect that doctoral students, as a discrete group, should have a success rate similar to that of other users. The hypothesis tested in this study is that the UCI Library collection includes 90 percent of the materials required by UCI doctoral candidates for their research. 
A random sample was selected from all dissertations completed at UCI during the last two quarters of the previous academic year. These were the most recent dissertations available for the study and provided a sufficiently large population from which to draw the sample. References cited in the selected dissertations were checked against the library's holdings. An assumption was made that the collection would not have changed significantly in the relatively short period since these particular students had completed their research.

The 36 dissertations from which the sample was drawn were divided into three broad fields of knowledge: the sciences, social sciences, and humanities. Within each group the dissertations were listed alphabetically by author. A systematic random sample was obtained by selecting every third dissertation listed, since the population was less than 100 . This yielded 12 for the study, with a total of 1,384 citations. Of the 12 dissertations, 3 fell into the humanities, 5 into the sciences, and 4 belonged in the social sciences.

The citations appeared either in the form of a bibliography, where each title was cited one time only, or as a list of references, in which some titles were repeated one or more times. For each dissertation the citations were divided into monographs, serials, or "other." Monographic titles, which included monographic series, were counted only the first time cited. Some citations were for editions other than those owned by UCI. Because the use of variant editions by the researchers could not be readily understood, a decision was made to count as held only those titles where the library's edition was the one cited or a later printing of the one cited, or else a simultaneous edition. Serial titles were determined according to the AACR2 definition, except for monographic series, and included journals, proceedings, annuals, and other materials issued periodically. These were considered to be duplicates and disregarded when the same volume for a particular title was cited more than once; when a different volume of that title was listed, it was counted as a separate citation, since many journals at
UCI have interrupted runs, with missing volumes.

The "other" category included a variety of unpublished materials, such as manuscripts, technical reports, and papers delivered orally or submitted for publication to unspecified journals. Titles falling into this group were ignored in the study because the library would not normally expect to collect this type of material; however, all dissertations cited were treated as monographs. Only 33 "other" citations were found, amounting to less than 3 percent of the total. Of the remainder, 207 were found to be duplicate citations, leaving 1,144 monographs and serials to be checked against the library's holdings.

Table 1 shows the distribution of citations broken down by field and by type of publication. The average number of citations per dissertation is 95.3 , while the range extends from 11 to 162 .

Each citation was checked against the card catalog and the order file, or the serials records. Those not located in the collection were reviewed for potential problems, such as works incorrectly cited, and where necessary, were rechecked. Finally, all of the data were reviewed for consistency and accuracy.

\section{RESULTS AND ANALYSIS}

The data obtained in the study were considered in two different ways. Table 2 treats all citations as equal and classifies them by field and by type of publication. It shows the percentage of monographic or serial citations held by the library in each of the three broad fields of knowledge. The table also shows the results for all monographs and all serials, as well as for each field irrespective of the type of publication. The percentage of successes for the entire list of citations checked is 90.4 , as shown in the "Complete Survey" line.

The standard deviation has been calculated for the sample sizes and observed percentages, assuming a binomial distribution. The error ratio column shows the difference between the observed percentage and the hypothesized 90 percent divided by the standard deviation of the sample. If the ratio is less than \pm 1.96 , then there is no statistically significant difference at the .05 probability level. In two 
TABLE 1

DISTRIBUTION OF CITATIONS BY

FIELD AND TYPE OF PUBLICATION

\begin{tabular}{|c|c|c|c|c|c|c|c|c|}
\hline \multirow{2}{*}{$\begin{array}{l}\text { Type of } \\
\text { Publication }\end{array}$} & \multicolumn{2}{|c|}{ Humanities } & \multicolumn{2}{|c|}{$\begin{array}{c}\text { Field } \\
\text { Sciences }\end{array}$} & \multicolumn{2}{|c|}{ Social Sciences } & \multicolumn{2}{|c|}{ Totals } \\
\hline & No. & $\%$ & No. & $\%$ & & $\%$ & No. & $\%$ \\
\hline Monographs & 249 & 91 & 53 & 14 & 130 & 27 & 432 & 38 \\
\hline Serials & 26 & 9 & 337 & 86 & 349 & 73 & 712 & 62 \\
\hline Totals & 275 & 100 & 390 & 100 & 479 & 100 & 1,144 & 100 \\
\hline
\end{tabular}

TABLE 2

ANALYSIS OF CITATIONS BY FIELD AND TYPE OF PUBLICATION

\begin{tabular}{lcccc}
\hline \hline Group & $\begin{array}{c}\text { No. of } \\
\text { Citations }\end{array}$ & \% Found & $\begin{array}{c}\text { Standard } \\
\text { Deviation }\end{array}$ & $\begin{array}{c}\text { Error } \\
\text { Ratio }\end{array}$ \\
\hline Monographs only & 432 & 88.2 & 1.55 & 1.163 \\
Serials only & 712 & 91.7 & 1.03 & 1.658 \\
Humanities & 275 & 92.0 & 1.64 & 1.223 \\
Sciences & 390 & 95.1 & 1.09 & $4.704^{\star}$ \\
Social sciences & 479 & 85.6 & 1.60 & $-2.746^{\star}$ \\
Complete survey & 1,144 & 90.4 & .87 & .441 \\
\hline
\end{tabular}

cases a significant ratio was obtained, as indicated by the asterisks.

Before analyzing these results, an alternate approach was considered. A potentially more useful way of looking at the results is to examine the mean or average of the percentage for students in each group, instead of the percentage of all citations in each group. This second approach is oriented toward the user and reflects the effectiveness of the library in meeting the needs of the individual student.

Table 3 shows the mean of the percentages of references that students in each group found in the library by type of publication and by field. It is clear that the data differ from that in table 2 . These differences occur because each dissertation does not have the same number of citations. In those cases where only a few references were cited, each of these has a greater weight in establishing the mean probability that the individual student's citations will or will not be found in the library than in the case of dissertations with a large number of citations.

The data in table 3 were analyzed to determine if there is any statistical basis for rejecting the 90 percent support hypothesis based on the experience of the individual students who formed the various sample groups. For each group the mean and standard deviations of the sample percentages were calculated, with the results shown in table 3 . Because of the small number of cases in each set of samples, a $t$ test was used to determine if there was a statistically significant difference from the hypothesized 90 percent support level. A .05 or less probability level was selected as significant. The $t$-test score and $.05 t$ value are also shown in table 3 . In only one case

TABLE 3

ANALYSIS OF DISSERTATIONS BY FIELD AND TYPE OF PUBLICATION

\begin{tabular}{lccccc}
\hline Group & $\begin{array}{c}\text { No. of } \\
\text { Dissertations }\end{array}$ & $\begin{array}{c}\text { \% of } \\
\text { Citations } \\
\text { Found }\end{array}$ & $\begin{array}{c}\text { Standard } \\
\text { Deviation }\end{array}$ & $\begin{array}{c}t \\
\text { Score }\end{array}$ & $\begin{array}{c}.05 \\
t \\
\text { Value }\end{array}$ \\
\hline Monographs only & 12 & 80.6 & 27.5 & 1.185 & 2.20 \\
Serials only & 12 & 90.2 & 7.3 & .100 & 2.20 \\
Humanities & 3 & 91.6 & 5.3 & .427 & 2.57 \\
Sciences & 5 & 93.7 & 3.2 & $2.352^{*}$ & 2.26 \\
Social sciences & 4 & 85.9 & 8.3 & .849 & 2.44 \\
Complete survey & 12 & 90.6 & 6.4 & .306 & 2.20 \\
\hline
\end{tabular}


was a significant deviation observed, as indicated by the asterisk.

In two cases in table 2 (sciences and social sciences) and one in table 3 (sciences), the observed percentages lie outside the range of expected values. Since the rest of the results confirm the hypothesis of 90 percent support, the possibility of other factors not considered by this study should be examined to determine why the observed support level for these two areas deviates from the expected norm, one above and the other below. These differences can be explained in two ways: first, as due to the sample size and the expected random distribution of results for the given size of sample; or second, because the actual support level for particular groups of users (such as graduate students in a given field) differs from the 90 percent hypothesized for the collection as a whole.

The data for each dissertation are given in table 4 . It shows that the 90 percent level is exceeded by all five of the dissertations in the sciences and by two out of three in the humanities, while three out of four in the social sciences fall below that level. The average number of citations found fell within \pm 7 percentage points of 90 percent except for dissertation no. 10 in the social sciences. In this exceptional case, the difference of 14 percent suggests the existence of special factors. A review of the dissertation indicates that it relied heavily on law journals for its references. Since UCI has no law school, these materials are collected on a very selective basis; thus many of the journal titles or specific volumes of these titles that were cited were not held by the library. Possible causes for the deviation in the science dissertations might be either the selection procedures for these areas, faculty influence in the selection of dissertation topics, or other factors not identified in this study.

\section{CONCLUSIONS}

The hypothesis that the UCI Library collection includes 90 percent of the materials required by $\mathrm{UCI}$ doctoral candidates for their research is accepted when the entire list of citations is considered. However, when the data are subdivided by field

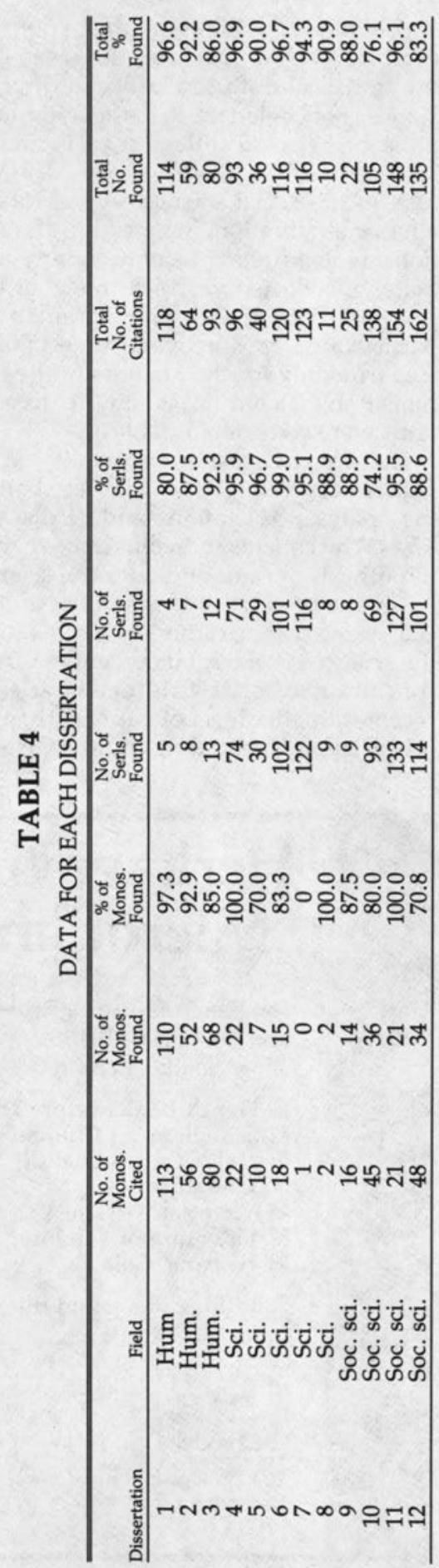


and/or type of publication, the hypothesis can be accepted only if all the cases pass the statistical test used. Since in three instances they failed the test, the hypothesis must be rejected unless special circumstances can be shown to exist. The one case in the social sciences represents an abnormal situation, where the dissertation involved relied heavily on a type of material collected very selectively at UCI due to the lack of a strong program in that particular field. Moreover, the test failure was true only for the analysis of the citations (table 2) and not when the dissertations were considered (table 3 ).

The other two instances of statistical test failure occurred for the sciences, both in the analysis of citations and of dissertations. The conclusion seems to be that the hypothesis does not hold for the sciences but is accepted for the humanities and social sciences. Since the sample mean for the sciences is above 90 percent, a further conclusion to be drawn is that the sciences receive a higher level of support than the other fields. This finding could be used as

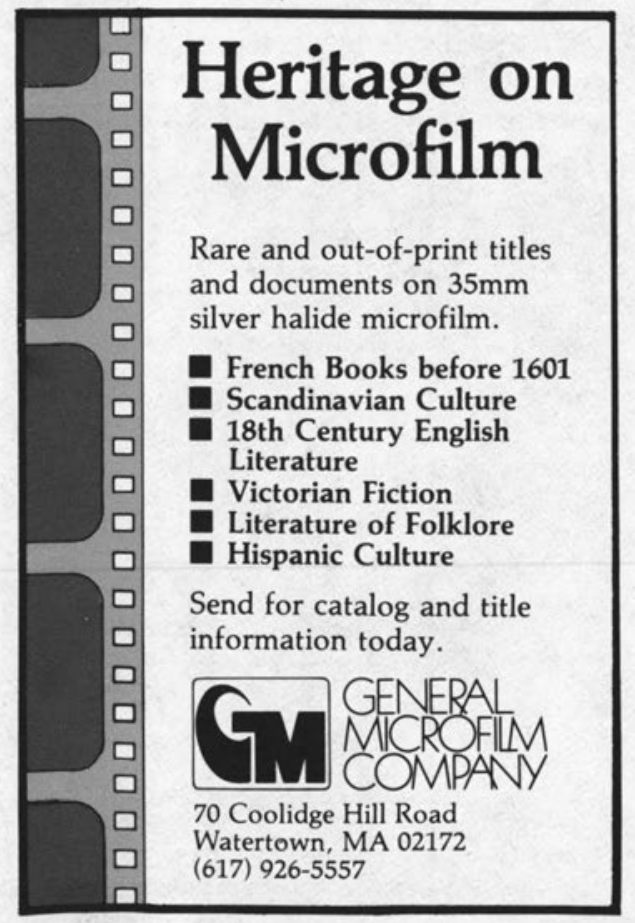

a factor in determining future allocation of library materials funding.

The data for each dissertation (table 4) showing that three of the four samples in the social sciences fall below the 90 percent level suggests that it might be useful to examine all of the social sciences dissertations in the original population of thirtysix to determine whether this pattern is typical. If it is, an effort could then be made to strengthen collection support in this particular field by increasing contacts with graduate students or by other appropriate means.

As one would expect, the humanities dissertations rely mostly on monographic references (91 percent), and the vast majority of the citations in the science dissertations are from journals ( 86 percent). The social sciences lie somewhere between those two fields, but with a much greater reliance on serials (73 percent) than on monographs. The data indicate that the level of support for serials at $\mathrm{UCI}$ is higher than for monographic materials. Although the difference does not seem particularly significant in the analysis of the citations, the analysis of dissertations shows a difference of 10 percent. The higher level for serials could be explained in a number of ways, including the fact that the universe of monographic titles is much larger and consequently more difficult to identify and to acquire, especially when retrospective materials are considered.

It appears that citation analysis can provide a valuable tool for evaluating collection support for doctoral research and that it can be applied to all fields in measuring research use of a library. Future studies of this type might include publication dates of materials cited when data are gathered. An analysis of the age of the publications cited in each field or in specific disciplines could provide helpful information for collection development decisions and could be useful as a predictor for establishing criteria for deselection in each field or discipline. It might also be interesting to devise a study that would compare the level of collection support for doctoral research with the level provided for faculty research, since selection information is gen- 
erally obtained from the faculty.

The findings of the UCI study tend to confirm other user studies indicating that libraries, on an average, acquire 90 percent of the materials requested by users.
Had the hypothesis been worded to state that the collection includes at least 90 percent of these materials, the correlation would have been even stronger.

\section{REFERENCES}

1. Sam E. Ifidon, "Qualitative/Quantitative Evaluation of Academic Library Collections," International Library Review 8:299-308 (1976).

2. Vernon W. Clapp and Robert T. Jordan, "Quantitative Criteria for Adequacy of Academic Library Collections," College \& Research Libraries 26:371-80 (Sept. 1965).

3. "Standards for College Libraries," College \& Research Libraries News 36:277-79 (Oct. 1975).

4. "Standards for University Libraries," College \& Research Libraries News 40:101-10 (Apr. 1979).

5. Known as the Voigt-Susskind formula and published in The University of California Libraries: A Plan for Development (Berkeley, Calif.: University of California, Office of the Executive Director of Universitywide Library Planning, 1977), p.118-22.

6. Charles J. Popovich, "The Characteristics of a Collection for Research in Business/Management," College \& Research Libraries, 39:110-17 (Mar. 1978).

7. W. Leslie Peat, "The Use of Research Libraries: A Comment about the Pittsburgh Study and Its Critics," Journal of Academic Librarianship 7:229-31 (Sept. 1981).

8. James C. Baughman, "The Library Ecology Problem" in K. Nyren, ed., Library Space Planning (LJ Special Report, no.1 [New York: Bowker, 1976]), p.46; Henry Voos, "Collection Evaluation," Collection Building 3, no.1:6-11 (1981).

9. Linda C. Smith, "Citation Analysis," Library Trends 30:83-106 (Summer 1981).

10. T. Saracevic, W. M. Shaw, Jr., and P. B. Kantor, "Causes and Dynamics of User Frustration in an Academic Library," College \& Research Libraries 38:7-18 (Jan. 1977); Ben-Ami Lipetz, "Catalog Use in a Large Research Library," Library Quarterly 42:129-39 (Jan. 1972); Daniel Gore, "Curbing the Growth of Academic Libraries," Library Journal 106:2183-87 (Nov. 15, 1981).

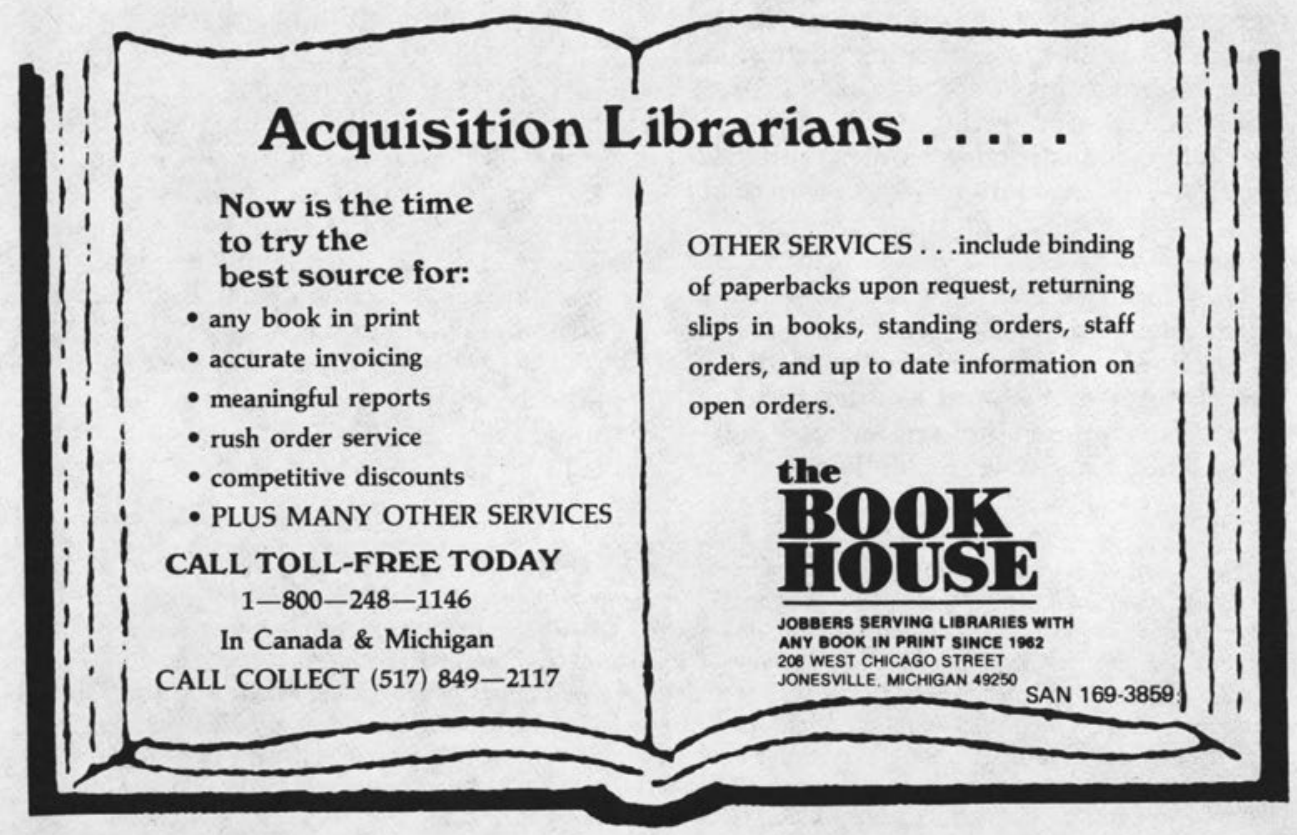

